\title{
int-Turas
}

website : bit.ly/buletinalturas

\section{Puritanisme dan Perkembangan Pendidikan Amerika Masa Kolonial}

\author{
Rusydi M. Yusuf \\ Universitas Darma Persada \\ Jakarta, Indonesia \\ er_em_ye@yahoo.com
}

\begin{abstract}
This study aims to know the influence of puritanism in the early development of education in America, especially in the 1600s to the beginning of American independence. It is a qualitative research with a library or documentary design relies on the main data of ideas, views, or beliefs taken from sources in the form of books, texts and other documents related to America puritanism. The collected data are analyzed qualitatively using concepts and theories relevant to the problem being discussed. The research reveals American puritanism was a religious reform movement in the mid of $16^{\text {th }}$ century aimed initially at purifying religious doctrines from the influence of Roman Catholicism. Although the puritans' thoughts had undergone ebb and flow, they still emerged nowadays in various activities, like in the president's inauguration speech. America puritanism was sourced from individual freedom values that influenced their life pattern. American puritanism was not only a religious belief, but it was also a philosophy of life. American puritanism has had a great influence on American cultural values, and the formation of the character of the American nation. It had also a great influence on the development of education in America since colonial era. It can be concluded that the puritanism influence greatly on American education system from the beginning of the first immigrants who settled in the new world in 1600s.
\end{abstract}

Keywords: puritanism; melting pot; doctrine; Grammar School; education

Doi: 10.15408/bat.v26i1.13841 


\section{Abstrak}

Penelitian ini bertujuan untuk menggali lebih dalam pengaruh puritanisme dalam pengembangan awal pendidikan di Amerika, khususnya pada 1600-an hingga awal kemerdekaan Amerika. Penelitian ini menggunakan metode penelitian kualitatif dengan rancangan penelitian yang berbentuk kajian kepustakaan. Data utama dalam penelitian ini gagasan, pandangan, atau keyakinan yang diambil dari sumber-sumber yang berbentuk buku-buku, naskah dan dokumendokumen lain yang berhubungan dengan puritanisme di Amerika. Data terkumpul dianalisis secara kualitatif dengan menggunakan konsep dan teori yang relevan dengan permasalahan yang sedang dibahas. Hasil penelitian memperlihatkan bahwa puritanisme Amerika adalah gerakan reformasi agama pada pertengahan abad ke-16, gerakan ini awalnya bertujuan untuk memurnikan doktrin agama dari pengaruh Katolik Roma. Walaupun hasil pemikiran kaum puritan selalu mengalami pasang surut, gagasan pemikiran mereka masih muncul dalam berbagai kegiatan, bahkan dalam pidato pelantikan presiden. Puritanisme di Amerika berpusat pada nilainilai kebebasan individu yang memiliki pengaruh terhadap pola kehidupan mereka. Puritanisme bukan hanya kepercayaan agama, tetapi juga filsafat kehidupan, kombinasi gaya hidup dan nilainilai. Berdasarkan temuan tersebut dapat disimpulkan bahwa doktrin puritanisme memberi pengaruh besar pada sistem pendidikan Amerika secara keseluruhan sejak awal imigran pertama yang menetap di dunia baru pada tahun 1600-an.

Kata kunci: puritanisme; melting pot; doktrin; Sekolah Tata Bahasa; pendidikan

\section{الملخص}

تهدف هذه الدراسة إلى تحليل تأثير التزمنية في التطور المبكر للتعليم في أمريكا، و خاصة في القرن

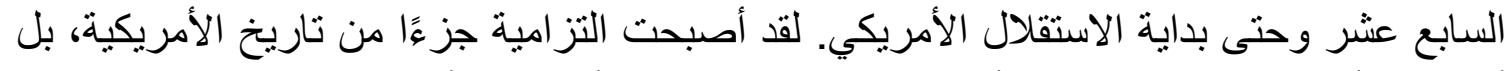

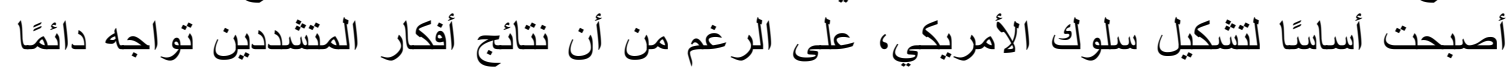

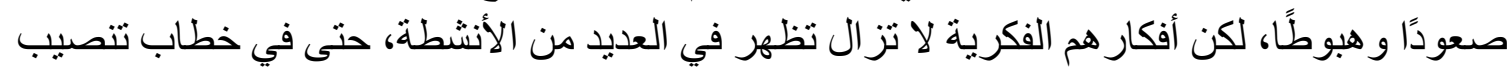
الرئيس. و تركز التزمتية في أمريكا على قيم الحرية الفردية، وقيمة التطهير لها تأثير على ألى أنماط

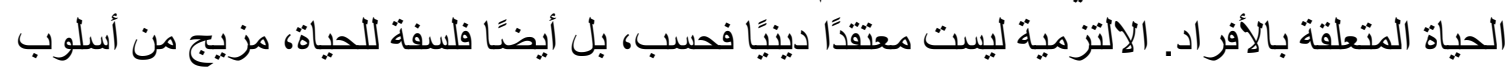

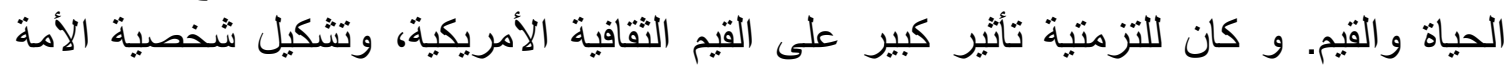
الأمريكية، وكان له تأثثر كبير على تطوير التعليم في أمريكا منذ العصور الاستعمارية. و تستخدم

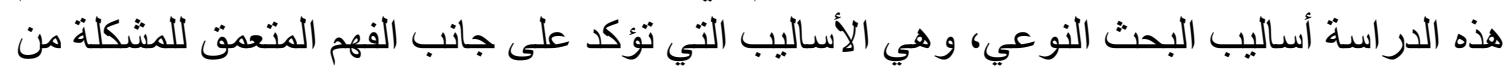

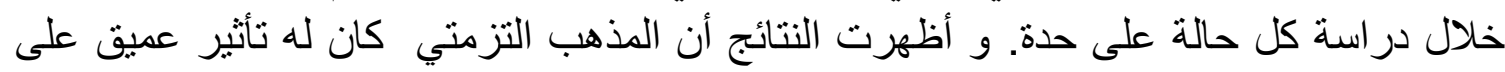
نظام التعليم الأمريكي ككل منذ بداية المهاجرين الأوائل الذين استقروا في العالم الجديد في القرن السابع عشر.

$$
\text { الكلمات الرئيسية: التزمنية؛ و عاء الانصهار ؛ العقيدة الدينية؛ مدرسة القواعد؛ التطوير التربوي. }
$$




\section{PENDAHULUAN}

Amerika merupakan bangsa yang memiliki tingkat kebhinekaan tertinggi di dunia, dalam artian masyarakatnya terbentuk dari hampir berbagai etnis yang ada di dunia. Sejak awal berdirinya, Amerika merupakan sebuah bangsa yang terdiri dari bangsa-bangsa. Gelombang imigran sejak kedatangan para pemukim pertama di awal abad 17 telah membentuk bangsa ini menjadi rumah dan labuhan harapan bagi jutaan orang dari berbagai penjuru dunia dengan beragam latar belakang budaya dan agama, perpaduan berbagai budaya dan latar belakang ini dikenal dengan teori Melting Pot. Teori tersebut pertama kali diperkenalkan pada tahun 1782, oleh J. Hector St. John de Crevecoeur, seorang imigran dari Perancis yang menggambarkan homogenitas demografis Amerika Serikat terdiri dari individu-individu dari semua bangsa yang mampu berubah dan berkembang menjadi ras manusia baru yang keturunannya suatu waktu akan menyebabkan perubahan besar di dunia. Dalam pandangannya, orang Amerika adalah peziarah barat yang membawa keterampilan industri dari Timur yang berakhir di Amerika Serikat (Mahmoud, 2013). Pandangan tersebut juga dikenal dengan sebutan Salad Bowl atau teori mosaik budaya. Pendangan tersebut menekankan terjadinya perpaduan dan integrasi beragam etnis penduduk Amerika menjadi satu kesatuan seperti perpaduan beberapa bahan sayuran untuk pembuatan salad. Model ini berbeda dengan konsep asimilasi budaya yang lebih tradisional dalam wadah peleburan. Sedangkan, dalam konsep mangkuk salad berbagai budaya Amerika tetap hidup dan tidak bergabung bersama menjadi masyarakat homogen tunggal. Imigran yang menyukai mangkuk salad berasimilasi dengan budaya dunia baru, tetapi pada saat yang sama mempertahankan praktik budayanya dari dunia lama mereka. Namun, mereka yang tidak berasimilasi, tetapi memilih untuk hidup di pinggiran, di kantong etnik di mana mereka dapat mempertahankan budaya dunia lama mereka (Mahmoud, 2013).

Selain keberagaman etnis yang telah membentuk bangsa ini, Amerika juga memiliki suatu doktrin pendidikan kuat yang juga telah membentuk sistem Pendidikan bangsa ini, yaitu doktrin puritanisme (McGoldrick, 2010). Puritanisme sejatinya merupakan gerakan keagamaan yang terjadi di Inggris pada abad ke 16, namun Gerakan ini tidak begitu mendapatkan tempat di Inggris, sehingga banyak dari anggota Gerakan ini yang di persekusi sehingga banyak dari mereka yang pergi berimigrasi ke New World, pada awal abad ke 17 para kelompok puritan ini pun mendarat di Amerika Utara dengan membawa paham puritanisme (Berghe, 2018).

Migrasi besar-besaran kelompok Puritan ke Amerika pada abad ke 17 menyebabkan perpaduan budaya yang kompleks dan bahkan sering terjadi konflik kekerasan antara orang Eropa dan pribumi asli Amerika, terutama di sepanjang pantai Atlantik, orang Eropa yang bermigrasi ke Amerika sebagian membawa penyakit menular seperti campak dan cacar, dimana penduduk asli Amerika tidak memiliki kekebalan dan penyakit ini banyak yang membinasakan mereka (Joshua, 2018).

Namun segala kendala yang dihadapi pada saat awal kendatangan kaum puritan ke Dunia Baru ini tidaklah menyurutkan niat mereka untuk mencari kehidupan di sana, dengan kedatangan berbagai kelompok dan latar belakang kaum immigran ini ke Amerika pada awal abad ke 16 tersebut, telah memberikan banyak perubahan terhadap pola dan sistem kehidupan. Dengan adanya doktrin dari kelompok puritan yang sangat kuat yang melatar belakangi terbentuknya bangsa dan negara Amerika pada awal kedatangan mereka ke dunia baru maka secara langsung atau tidak langsung sistem pendidikan mereka juga terbentuk dengan sendirinya, dari doktrin tersebut maka dari itulah Amerika menjadi negara yang maju dan disegani baik pada masa itu maupun pada saat ini. 
Sekolah pertama yang muncul digagas oleh para pemuka agama di mana seorang anak diharapkan sudah mampu membaca dan menulis meskipun mereka hanya belajar di rumah, kelompok belajar ini yang dikenal sebagai Dame School, selesai dari Pendidikan di Dame School maka mereka bisa melanjutkan ke Latin School atau Latin Grammar School yang merupakan persiapan menuju Pendidikan di Perguruan Tinggi, tahapan selanjutnya setelah lulus dari Latin Grammar School mereka bisa masuk ke Harvard College yang merupakan perguruan tinggi pertama yang berdiri pada masa awal kolonial Amerika.

Untuk bisa lebih memahami doktrin puritanisme terhadap perkembangan Pendidikan di Amerika pada masa colonial, maka melalui tulisan singkat ini akan dibahas bagaimana kelompok puritan membangun sistem Pendidikan di Amerika sejak kedatangan ke Amerika, meskipun Amerika merupakan hutan belantara yang belum terjamah oleh manusia, tapi dengan doktrin John Winthrop dalam sebuah pidato yang disampaikan sebelum menjalankan ekspedisi puritan di benua Amerika ketika mereka baru saja mendarat di pelabuhan Boston tahun 1630 dengan mengatakan We shall be as City upon a Hill (Daniel, 1990) hal yang serupa juga disampaikan oleh Winthrop di atas kapal Arabella ketika mereka masih dalam pelayaran menuju benua Amerika we shall be as a city upon a hill, the eyes of the world are upon us, (Bercovitch, 1998) maka kaum pendatang menguatkan tekad mereka untuk membuka hutan belantara dengan harapan akan memperoleh kehidupan yang lebih baik dari sebelumnya. Mereka sadar untuk dapat membangun sebuah bangsa yang besar dan mewujudkan mimpi John Winthrop tersebut tidaklah mudah, maka hal pertama yang harus dibangun adalah sistem Pendidikan. Dengan sistem Pendidikan yang baik dan kuat maka cita-cita John Winthrop tersebut akan dapat dicapai.

\section{METODE}

Dalam penelitian ini dipergunakan metode penelitian kualitatif, yaitu suatu metode yang lebih menekankan kepada aspek pemahaman secara mendalam terhadap suatu masalah dengan mengkaji masalah secara kasus perkasus, sebagaimana yang dikatakan oleh Moleong yang dikutip oleh Herdiansyah Haris (Haris, 2010) bahwa penelitian kualitatif adalah suatu penelitian ilmiah, yang bertujuan untuk memahami suatu fenomena dalam konteks sosial secara alamiah dengan mengedepankan proses interaksi komunikasi yang mendalam antara peneliti dengan fenomena yang diteliti.

Saryono juga mengatakan (Saryono, 2010) bahwa Penelitian kualitaif merupakan penelitian yang digunakan untuk menyelidiki, menemukan, menggambarkan, dan menjelaskan kualitas atau keistimewaan dari pengaruh sosial yang tidak dapat dijelaskan, diukur atau digambarkan melalui pendekatan kuantitaif. Sementara menurut Bodgan dan Taylor yang dikutip oleh Bambang Setiyadi, penelitian kualitatif merupakan prosedur penelitian yang menghasilkan data deskriptif berupa kata-kata tertulis (Setiyadi, 2006). Untuk memperoleh penelitian yang komprehensif diperlukan data, dalam penelitian ini data diperoleh dari bahan-bahan pustaka atau data dokumentasi yang berkaitan langsung atau tidak langsung dengan objek selanjutnya data tersebut akan dioleh dan dianalisis untuk diambil suatu pembuktian dan kesimpulan. 


\section{TEMUAN DAN PEMBAHASAN}

Puritanisme Amerika berawal dari Inggris yang merupakan gerakan reformasi agama pada pertengahan abad 16, gerakan ini pada awalnya bertujuan untuk melakukan penyucian (Kang, 2009) kembali terhadap doktrin keagamaan di Inggris dari pengaruh ajaran Katolik Roma. Lambat laun paham Puritan ini semakin berkembang di Inggris, terutama di daerah Essex. Kaum puritan ini sangat memegang teguh doktrin keagamaan mereka dalam kehidupan sehari hari, sehingga mereka ingin menjadikan ajaran puritanisme untuk dijadikan ajaran resmi di seluruh Inggris, karena keinginan tersebut maka terjadilah perang saudara tahun 1641-1651 (Yuliati, 2015). Perang diawali oleh peristiwa the interregnum (Craig, 2018) yaitu suatu konflik yang terjadi antara parlemen dan raja Charles 1. Kelompok puritan di Inggris terbagi ke dalam dua kelompok, kelompok pertama mereka yang ingin mereformasi gereja Katolik Roma dan mendirikan gereja Anglikan dan kelompok kedua adalah mereka yang ingin memisahkan diri dari gereja Anglikan, kelompok kedua ini dikenal sebagai Puritan Separatis (Junaidi, 2007).

Setelah usai perang saudara di Inggris, kelompok puritan separatis bebas untuk mengembangkan ajaran mereka, karena parlemen yang berkuasa saat itu di bawah pimpinan Oliver Cromwell (Craig, 2018) sangat berpihak kepada kelompok puritan ini. Pengaruh Charles I dan sekutunya mulai hilang pada $1651 \mathrm{M}$, apalagi setelah Charles I dijatuhi hukuman mati di bawah keputusan/perintah yang dikeluarkan oleh Rump Parliament pada tahun 1649. Setelah peristiwa tersebut, kaum revolusioner membangun pemerintahan parlementer yang perlahan-lahan terkonsolidasi dalam kekuasaan Oliver Cromwell, yang mecapai kejayaannya pada periode yang dikenal sebagai Protektorat (1653-1659). Sebagai Pelindung Tuhan, Cromwell memiliki lebih banyak otoritas seperti raja. Setelah keruntuhan pemerintahan pada 1659, keluarga kerajaan Stuart, di bawah Charles II, kembali memerintah dalam bentuk kerajaan, dengan beberapa perubahan, yakni kekuasaan dibagi antara Parlemen dan raja selama masa pemulihan pada tahun 1660 (Junaidi, 2007).

Namun setelah kematian Cromwell, kelompok ini menjadi tidak berkembang lagi, kelompok ini mulai bangkit kembali setelah kolonisasi di Amerika oleh bangsa-bangsa Eropa mulai berkembang, maka kelompok ini mulai melakukan migrasi ke Amerika. Mereka memperoleh izin dan sponsor dari Virginia Company, sebuah kongsi dagang Inggris untuk mendirikan pemukiman di daerah Virginia. Para pengungsi ini menyebut diri mereka sebagai Peziarah (Pilgrims) dari Belanda berangkat ke Southampton, Inggris. Kemudian dilanjutkan dengan berlayar ke Amerika. Di sisi lain kaum puritan ini juga beranggapan bahwa kedatangan mereka ke benua Amerika merupakan perintah Tuhan untuk menyelamatkan kesucian ajaran agama mereka, mereka menganggap bahwa Amerika adalah sebagai tempat yang dijanjikan Tuhan untuk mereka, maka pelak lagi mereka mengatakan Amerika merupakan surga baru tempat mereka mensucikan agama dan mereka juga menyatakan bahwa merekalah sebagai the Chosen People yang akan membangun dunia baru Amerika (Junaidi, 2007).

Berdasarkan izin yang diberikan oleh Virginia Company, pada tahun 1620 kaum Puritan berlayar dari Inggris menuju Jamestown, Virginia dengan menggunakan Kapal Mayflower. Akan tetapi kapal mereka terhantam badai, sehingga mereka terbuang jauh ke arah utara. Mereka mendarat di Semenanjung Cape Cod, Massachusetts. Akhirnya mereka menetap di Plymouth, Massachusetts di luar kekuasaan Virginia Company sehingga status hukum mereka tidak jelas. Mereka menyadari hal ini, sehingga mereka terdorong untuk membuat perjanjian. Perjanjian ini dikenal sebagai Mayflower Compact (Requena, 2019). Mayflower Compact merupakan salah satu dokumen resmi 
pemerintahan paling awal di Amerika. Tujuan dari perjanjian tersebut adalah untuk menjamin kelangsungan hidup dan kerja sama para pendatang dengan pemerintah. Mereka sebagai pendatang baru mempunyai dasar hukum untuk tetap tinggal jika ada perubahan kekuasaan pemerintahan selanjutnya. Selain itu, mereka dapat membentuk jemaat tetapi tetap harus mematuhi raja. Jadi, perjanjian tersebut lebih banyak berkaitan dengan kehidupan masyarakat sipil daripada masyarakat agama.

Perjanjian tersebut mendorong kaum Puritan di Inggris yang banyak mendapat tekanan dari pemerintah untuk pindah ke Amerika. Kaum Puritan Inggris yang bermigrasi ke Amerika mempunyai motivasi utama yaitu agama. Karena mereka tidak mampu melakukan reformasi terhadap gereja di Inggris mereka membutuhkan tempat baru untuk menerapkan ajaran dan keyakinan mereka secara bebas. Selain itu mereka juga ingin membentuk sebuah negara teokrasi dan memimpinnya.

Kelompok puritan yang masuk ke benua baru Amerika mendirikan koloni-koloni baru (Kang, 2009). Yang pertama berdiri adalah koloni Plymouth tahun 1620, kemudian menyusul koloni Massachusetts 1628, koloni New Hampshire 1629, koloni Connecticut 1633, koloni Maine 1635 koloni Rhode Island 1636, dan koloni New Heaven 1638. Pada masa selanjutnya terbentuklah tiga belas koloni asli yang pada akhirnya menjadi Amerika Serikat setelah perang revolusi. Inggris, yang mengalahkan Belanda dan Perancis, selama periode kolonialisasi puritanisme memberikan pengaruh yang sangat besar terhadap perkembangan pemikiran di bidang keagamaan dan pola budaya. Menurut Kang (2009) puritanisme itu tidaklah hanya sekedar keperayaan tentang keagamaan semata, tapi ia juga merupakan filsafat kehidupan, suatu kombinasi antara gaya kehidupan dan nilainilai. Puritanisme telah memberikan pengaruh yang besar terhadap nilai-nilai kebudayaan Amerika, dan terbentuknya karakter bangsa Amerika, di antara nilai-nilai utama yang menonjol adalah nilai nilai individualisme, egalitarianisme, nilai optimisme, yang semuanya bersumber dan berasal dari doktrin puritan sejak jaman kolonial. Adapun bidang yang mendapatkan perhatian yang paling besar adalah pendidikan yang merupakan isu yang sangat penting dalam pembangunan di Amerika (Gao, 2014).

Ajaran puritanisme ini memberikan pengaruh yang sangat besar dalam bidang pendidikan, karena dasar pemikirannya adalah bahwa setiap anak yang lahir harus dapat membaca kitab suci (Hiatt-Michael, 1994). Oleh karena itu, setiap anak diwajibkan mampu membaca agar mereka memahami kitab suci. Begitu juga dengan orang tua, khususnya seorang ibu, harus mengajarkan anak-anak mereka membaca. Sering kali seorang ibu akan mengajarkan anak mereka membaca sambil mengarjakan pekerjaan rumah tangga. Namun, tidak semua orang tua mampu mengajari anak-anak mereka sendiri karena keterbatasan pengetahuan yang mereka miliki, maka lahirlah apa yang disebut Dame School. Ini merupakan pendidikan informal yang ada pada waktu itu, di mana seorang anak akan dititipkan kepada seorang ibu yang dikenal sebagai Dame untuk diajarkan membaca, menulis dan berbagai pekerjaan rumah tangga khusus untuk anak perempuan. Pelaksanaan kegiatan pendidikan tersebut lebih banyak terjadi di dapur, terutama untuk mengajarkan anak-anak perempuan tugas-tugas atau pekerjaan rumah tangga, seperti memasak, mencuci, membersihkan dan merapikan rumah; sedangkan anak laki-laki lebih diarahkan untuk mengikuti pendidikan di kota atau pendidikan formal (Madigan, 2009).

Anak-anak yang berusia 6-8 tahun yang telah menyelesaikan pendidikan di Dame School sudah mampu untuk membaca dan menulis, dan pada usia 9 (sembilan) tahun mereka diajarkan bagaimana harus menghadapi kehidupan yang sesungguhnya. Orang tua akan memiliki 3 (tiga) pilihan yang harus ditentukan untuk pendidikan anak laki-laki 
mereka. Pertama, mengarahkan dan memberikan pelajaran tambahan kepada mereka khususnya pelajaran membaca sebagai persiapan masuk Latin School atau Latin Grammar School. Umumnya, anak dipersiapkan hanya untuk menjadi seorang pemuka agama yang mampu memahami al-Kitab dengan baik. Kedua, mereka akan diberikan pelatihan keterampilan tertentu di rumah oleh ayah mereka untuk menghemat biaya pendidikan yang harus dikeluarkan. Ketiga, mereka akan dimasukan sekolah vokasi di mana mereka akan dilatih untuk bekerja, namun biasanya sekolah ini membutuhkan biaya yang cukup besar. Sekolah-sekolah yang didirikan umumnya diselenggarakan dengan memperhatikan kelas sosial masyarakat pada waktu itu, terutama untuk wilayah-wilayah perkebunan sebagaimana yang telah terjadi di Inggris. Sekolah-sekolah yang diperuntuk bagi kelas sosial menengah ke atas dibiayai secara mandiri oleh oleh orang tua yang anakanak mereka menempuh pendidikan di sana. Adapun sekolah-sekolah bagi mereka yang kelas sosialnya rendah didanai oleh para dermawan yang peduli akan pentingnya pendidikan dasar bagi penduduk Amerika dengan dukungan dan pengawasan sepenuhnya oleh orang tua terakit dengan tatakelolah, pengembanagan kurikulum, dan pelajaran agama.

Berbeda dengan Dame School, Latin School atau Latin Grammar School merupakan lembaga pendidikan yang dirancang bagi mereka yang mampu secara ekonomi karena tujuan lulusannya adalah menjadi seorang pemimpin baik di gereja, pemerintahan maupun di pengadilan (Hiatt-Michael, 1994). Mata pelajaran bahasa Latin, Yunani dan kesusasteraan diajarkan bersamaan dengan pelajaran agama yang didasari oleh reformasi protestan. Yang tertarik dengan pendidikan ini hanyak anak laki-laki dari kelas menengah ke atas.

Latin Grammar School mempersiapkan anak-anak agar mampu melanjutkan pendidikan tinggi di Harvard University. Universitas ini didirikan pada tahun 1636 oleh seorang pimpinan pengadilan umum di Massachusetts Bay Colony yaitu John Harvard (Bolton, 1995). Pada awal berdirinya, universitas ini masih berpegang pada sistem pendidikan klasik yang diselenggarakan di universitas-universitas Inggris sesuai dengan filosofi puritanisme. Harvard didirikan untuk menyiapkan pemimpin masa depan yang membutuhkan pendidikan melalui proses klasik dan teologis. Pada perguruan tinggi tersebut seluruh siswa diwajibkan untuk memiliki kompetensi bahasa Latin dan Yunani, tata bahasa, logika, retorika, matematika, geometri, astronomi, etika, filsafat, dan ilmu pengetahuan alam. Agar pendidikan tinggi tersebut dapat berlangsung dengan baik, maka setiap keluarga yang tinggal di New England dikenakan kewajiaban untuk memberikan sumbangan sebesar 1 Shilling atau yang setara; apabila tidak memiliki uang maka mereka boleh membantu dengan hasil pertanian (Shipton, 1958).

Para pendatang pada awalnya menciptakan sistem sekolah berbasis kelas sosial ekonomi mengikuti apa yang mereka dapatkan di Eropa (Vinovskis, 1987). Anak lakilaki dan perempuan dari kalangan sosial ekonomi rendah menghadiri sekolah dasar di mana mereka belajar membaca, menulis, berhitung, dan agama. Sementara itu, anak lakilaki dari kalangan atas mengikuti pendidikan di sekolah tata bahasa Latin, agar dapat melanjutkan pendidikan di perguruan tinggi (Bolton, 1995), dan mempelajari bahasa Inggris secara langsung dari lingkunan keluarga dan masyarakat. Para siswa memasuki sekolah tata bahasa Latin pada usia delapan tahun dan menyelesaikan studinya pada usia lima belas atau enam belas tahun. Mereka belajar dari penulis Latin seperti Cicero, Terence, Caesar, Livy, Vergil, dan Horace, sedangkan informasi lainya mereka diajari oleh penulis Yunani seperti Isokrates, Hesiod, dan Homer. Para pengampu bahasa Latin 
yang mengajar di sekolah ini kebanyakan lulusan perguruan tinggi yang dibayar dengan lebih baik dan menikmati status sosial yang lebih tinggi daripada guru sekolah dasar.

\section{Koloni Inggris Baru}

Koloni Baru Massachusetts adalah wadah untuk pengembangan ide-ide dan lembaga pendidikan Amerika (Hiatt, 1994). Massachusetts memberlakukan penyelenggaraan pendidikan formal yang pertama di British Amerika Utara. Penjajah Massachusetts percaya bahwa orang-orang berpendidikan yang mengerti ajaran agama seperti dijelaskan oleh tokoh-tokoh Puritan mereka, mampu menahan diri untuk melakukan perbuatan jahat yang merugikan orang lain. Jadi, sesuai dengan imbauan pandangan para tokoh Protestan mereka, sekolah agama atau gereja difungsikan untuk menekankan kegiatan membaca, menulis, dan memahami ajaran agama yang pokok dan penting. Selain urusan agama, mereka juga memperhatikan pentingnya anak-anak mereka memiliki penguasaan keterampilan atau kemampuan bekerja, serta pemahaman terhadap aspek aturan-aturan yang berlaku dalam pemerintahan, sehingga mereka memahami hak dan kewajiban secara baik dalam kehidupan sosial kemasyaratkan dan kenegaraan (Jernegan, 1918).

Kaum puritan mulai mendirikan sekolah pada tahun 1642 seiring dengan ketetapan pengadilan umum Massachusetts yang mengesahkan undang-undang yang meminta orang tua dan wali memastikan bahwa anak-anak dalam perawatan dan pengawasan mereka untuk belajar membaca dan memahami prinsip-prinsip agama dan hukum persemakmuran itu. Hal tersebut dapat dilihat dari pernyataan bahwa, "on April 14, 1642, the Massachusetts General Court passed the Massachusetts School Law of 1642, which mandated a form of compulsory education for students so they could read and understand the scriptures and the law of commonwealth" (DeMitchell, 2014). Pentingnya pelajaran agama bagi anakanak mereka diperkuat kembali oleh undang-undang Old Deluder Satan pada tahun 1647. Undang-undang tersebut memstikan bahwa orang tua tidak boleh mengabaikan pendidikan anak-anak mereka, terutama pelajaran agama dan sastra yang membangun karakter anak-anak mereka. Selain itu, orang tua juga didorong untuk membekali anakanak kemampuan berbahasa Latin agar mampu melanjutkan pendidikan di Harvard College.

Sekolah Puritan dibangun dan dilaksanakan dengan tujuan penguatan kehidupan ekonomi dan agama. Bagi mereka, masyarakat Puritan yang baik adalah mereka yang berhasil menjadi pengusaha dan petani yang rajin dan hemat yang menghadiri gereja, membaca Alkitab, dan bekerja keras. Adanya jalinan antara nilai-nilai agama dan pekerjaan, sekolah Puritan menekankan nilai-nilai ketepatan waktu, kejujuran, ketaatan kepada otoritas, dan kerja keras, pendidikan Amerika terus menekankan hubungan antara pendidikan dan produktivitas ekonomi. Setelah Teologi John Calvin (McGoldrick, 2010). Pada mulanya pendidikan awal bagi kaum puritan dimulai dari rumah, hal ini berangkat dari ide Covenant Household (Bolton, 1995; Vorster, 2016) karena seorang anak terlahir dengan dosa maka keselamatan setiap anak dan keindahan akhlaknya sudah tertanam di setiap hati orang tua. Menyadari akan hal tersebut para orang tua percaya bahwa Pendidikan ana-anak mereka terutama Pendidikan agama merupakan kewajiban mereka bahkan para orang tua juga membayangkan bagaimana ketika nanti di akherat ditanya tentang pedidikan anak-anak mereka, kalau mereka mengabaikannya tentu akan ditanya tanggungjawabnya oleh sang pencipta (Kim, 2019). Itulah sebabnya, ketika kaum puritan sampai di dunia baru mereka memprioritaskan dalam mendirikan sekolah bagi anak-anak mereka agar memperoleh pengetahuan agama dan keterampilan. 
Kaum puritan memiliki semangat dan doktrin yang kuat pada Covenant Theology (Kim, 2019), yakni seorang anak sudah memiliki dosa sejak ia kecil. Oleh karen itu, sekolah berkewajibkan untuk mengajari seorang anak agar terlepas dari dosa-dosa masa lalu tersebut. Berdasarkan ajaran puritanisme, Bible merupakan pusat ilmu pengatahun dan pendidikan. Untuk itu para pemuka agama menginginkan pendidikan dan pencerahan bagi semua orang. Mereka berharap semua orang mampu untuk membaca dan memahami Al-Kitab untuk diri mereka sendiri.

Kemampuan membaca Al Kitab merupakan kewajiban dalam kehidupan sehari hari agar menjadi seorang yang saleh. Pendidkan bagi generasi selanjutnya sangatlah penting untuk tetap mempertahankan ajaran yang baik dan menuju kehidupan sosial yang lebih baik. Ini merupakan pandangan dan visi dari Marthin Luther yang menyatakan bahwa menuntut ilmu adalah hal yang utama bagi setiap orang. Oleh karena ia selalu mengajari anak-anaknya untuk membaca kitab suci (Kenneth \& C. Jr, 2013). Marthin Luther selalu merasa berabahagia ketika melihat anak-anaknya mampu menguasi semua pelajaran yang diberikan di sekolah, menjalankan ajaran agama secara baik, serta dapat bermain bersama sesamanya menghabiskan masa kecil dengan riang dan gembira.

Dalam ajaran Puritan, tujuan utama dari pendidikan adalah memelihara dan mengembangkan ajaran puritan itu sendiri, maka dari itu pada sejarah awal bangsa Amerik Pendidikan gratis itu ditujukan kepada kelompok anak-anak. Kemudian pada tahun 1635 Puritan mulai mendirikan sekolah formal yang dikenal dengan Roxbury Latin School, kemudian pada tahun 1636 didirikan sekolah tinggi yaitu Harvard College. Kemudian pada tahun 1647 Undang-undang Massachusetts (Bolton, 1995) mengamanatkan bahwa setiap kota yang berpenduduk 50 kepala keluarga (Hiatt-Michael, 1994) agar mendirikan sekolah dasar, dan kota yang memiliki 100 kepala keluarga atau lebih harus mendirikan Grammar School sekolah ini merupakan sekolah persiapan bagi anak laki-laki untuk masuk ke perguruan tinggi. Karena penghargaan yang tinggi terhadap Pendidikan, makanya hanya sedikit saja orang di New England yang mengalami buta huruf di dibandingkan negara bagian lain di Amerika waktu itu.

Pendidikan pada awal negara Amerika bermula dari rumah yang bertumpu kepada seorang ibu dan berakhir di ladang pertanian di sisi seorang ayah. Pendidikan membaca pertama kali dilakukan oleh seorang ibu di rumah, dan karena keterbatasan kertas tak jarang seorang ibu menulis kata-kata dari abu tungku setiap kali mengajari anak-anak mereka mebaca. Pendidikan di rumah sudah merupakan hal yang umum di Amerika maka dari itu kebanyakan anak sudah pandai membaca sebelum mereka masuk sekolah formal, sebagaimana yang dikatakan oleh Ralph Walker bahwa sudah merupakan suatu kelaziman bagi anak-anak untuk diajarkan membaca di rumah sebelum mereka masuk sekolah formal. Pada keluarga kelas menengah, seorang ibu diharapkan tidak buta huruf dan menguasi pengetahuan dasara agar mampu mengajarkan anak-anak membaca dan menulis (Peterson, n.d.) Pada masa awal sejarah bangsa Amerika, anak-anak sudah diajarkan dasar-dasar pendidikan akademis seperti membaca, menulis, dan bagaimana memecahkan masalah kehidupan, dengan demikian maka tidak ada anak yang buta huruf.

\section{Pendidikan Dasar}

Pendidikan di Amerika awal dimulai di rumah, di pangkuan dan pelukan seorang ibu, serta seringkali berakhir di ladang jagung atau gudang di sisi ayah. Tugas mengajar membaca biasanya jatuh ke tangan ibu; setiap orang tua berusaha untuk memberikan pendidikan keagamaan di rumah. Namun, karena keterbatasan pengetahuan yang dimiliki 
atau kesibukan mereka bekerja di ladang dan pabrik, mereka tidak mampu mengajari anak-anak mereka bagaimana cara membaca, menulis, dan menguasai pengetahuan dasar.

Oleh karena itu, untuk meningkatkan kemampuan anak-anak dalam hal membaca, pada tahun 1642 Colony Massachusetts mengeluarkan sebuah undang-undang yang mewajibkan kepada orang tua untuk mengajari anak-anak mereka untuk membaca, memahami prinsip-prinsik keagamaan dan hukum dasar bernegara. Di sisi lain pemerintah juga menawarkan kepada para orang tua yang tidak mampu untuk memperoleh pendidikan gratis agar anak-anak agar dapat membaca, menulis, dan menguasai pengetahuan dasar. Selain itu, undang-undang tersebut juga mendorong melakukan kegiatan berdarma untuk mendanai penyelenggaraan pendidikan bagi anakanak mereka. Setiap 50 keluarga dapat bekerja bersama-sama mendanai pembiayaan guru-guru yang tidak bisa dibayarkan oleh pemerintah local. Jadi, pendidikan dasar bagi anak-anak mereka tetap berlangsung meskipun ada keterbatasan pendanaan dari keluarga tidak mampu dari pembiayaan yang bersumber dari pemerintah.

\begin{abstract}
"As early as 1642, Massachusetts colony, the leading colony regarding educational issues, passed a law which required all parents to provide their children with education in reading, religion, and a trade. When local leaders observed that some parents were not teaching their children to read, they pressed for a law which mandated that all towns of 50 inhabitants or more hire a teacher who could be paid out of local funds (Hiatt-Michael, 1994).
\end{abstract}

Karena keterbatasan wadah untuk menulis dan membaca maka untuk mempermudah anak-anak dalam membaca dan menulis maka dipergunakanlah hornbook, yakni tulisan atau teks mengenai hal-hal yang penting terukir pada papan kayu, tulang, batu, atau kulit (Bolton, 1995). Seorang ibu dapat juga menggunakan debu atau sejenis untuk mengajarkan kepada anak-anak membaca. Biasanya bacaan yang diajarkan adalah isi pidato keagamaan dan al-Kitab yang tidak asing bagi anak-anak setelah mendengarnya di gereja atau di kebaktian keluarga. Tentu saja hal tersebut akan membantu mereka segera menguasai keterampilan membaca. Selain Al-kitab buku-buku karya sastra yang berkualitas seperti Pilgrim's Progress John Bunyan juga menjadi materi membaca anakanak, termasuk The New England Primer, dan Divine Songs Isaac Watt juga dipergunakan untuk proses belajar mengajar membaca. Dari daftar bacaan tersebut, para pendiri negara ini dan generasi mereka mempelajari nilai-nilai dasar dalam kehidupan mereka. Dalam Against Idleness and Mischief, misalnya, mereka belajar tanggung jawab individu di hadapan Tuhan dalam bidang pekerjaan dan pembelajaran.

Pendidikan dasar yang berkembangn masa awal merupakan pendidikan informal yang berlangsung di dalam keluarga atau kelompok kecil masyarakat yang teruma diarahkan pada pemgembangan kemampuan membaca anak. Anak laki-laki memperoleh perhatian yang lebih besar dibandingkan dengan anak perempuan. Setalah mereka menguasai keterampilan membaca, anak laki-laki didorong untuk menguasai keterampilan yang bermanfaat untuk bekerja. Sedangkan anak perempuan, lebih diarahkan untuk menguasai keterampilan untuk melaksanakan pekerjaan rumah tangga, atau keterampilan lain, seperti memasak atau merajut.

\title{
Pendidikan Grammar School
}

Anak laki-laki yang tidak memiliki kemampuan membaca dengan baik, mereka diarahkan untuk bekerja membantu orang tua mereka di ladang; atau mereka akan belajar bagaimana cara berdagang atau membuka usaha. Adapun bagi mereka yang memiliki 
kemampuan membaca yang lebih baik, mereka didorong untuk melanjutkan pendidikan di sekolah grammar. Tujuan utama didirikannya Pendidikan Grammar School adalah mendidik anak laki-laki agar mampu membaca sehingga mereka dapat melanjutkan pendidikan mereka ke tingkat universitas. Pada kelas Grammar School mata pelajaran yang mereka pelajari adalah tata Bahasa Inggris, Bahasa Latin dan Bahasa Yunani, sastra, dan matematika. Mereka yang belajar di Pendidikan Grammar School berusia 10-14 tahun. Dalam mata pelajaran sastra mereka belajar karya sastra dari sastrawan klasik seperti karya Ovid, Horace, Virgil, Cicero dan Seneca. Setelah mereka menyelesaikan pelajaran di Pendidikan Grammar School mereka dapat memasuki universitas (Bolton, 1995).

Proses belajar mengajar bagi anak lak-laki sangatlah ketat sepanjang musim panas sekolah akan dimulai pada jam 6 pagi dan berakhir pada jam 5 sore dengan 2 jam untuk beristirahat pada siang hari. Dalam satu minggu mereka akan belajar selama 5 hari, dalam setahun mereka belajar selama 44 minggu. Apabila mereka melanggar ketentuan yang sudah ditetapkan, maka hukumannya adalah dipukul dengan batang tebu sebanyak 50 kali (Cothran \& Lowe, 2011).

\section{Pendidikan Tinggi}

Tidak berapa lama setelah orang-orang Eropa mendarat di benua Amerika, para tokoh pendidikan mereka yang mayoritas merupakan kaum puritan mendirikan lembaga pendidikan tinggi pertama (Skeete, 2010). Pendidikan Tinggi yang mereka dirikan ini dikenal sebagai perguruan tinggi kolonial, Harvard College, pada tahun 1636 di Cambridge, Massachusetts. Harvard College sekarang dikenal sebagai Universitas Harvard dan merupakan salah satu perguruan tinggi paling terkenal di dunia. Perguruan tinggi kolonial lainnya termasuk College of William and Mary, Universitas Yale, Universitas Princeton, Universitas Columbia, Universitas Brown, Universitas Rutgers, dan Universitas Dartmouth (Kraus, 1961).

Pendidikan tinggi pada awal berdirinya negara Amerika berasal dari pemikiran kaum Puritan, antara lain William Perkins dan William Ames, yang merupakan tokoh penting pendirian pendidikan tinggi saat itu. Pendidikan tinggi diupayakan agar terintegrasi antara pengetahun dan agama supaya mereka dapat melihat dunia luar; dan mengambil peran yang lebih besar. Dalam proses belajar mengajar di pendidikan tinggi, para tenaga pengajar lebih banyak menggunakan logika sebagai dasar pemikiran dengan berlandaskan kita suci, sehingga gerakan puritan mengarah kepada gerakan ilmu pengetahun dan teknologi.

Pendidikan tinggi awal seperti Harvard didirikan untuk menyediakan layanan pendidikan untuk para pendeta, akan tetapi setelah Revolusi Amerika, perguruan tinggi mulai memperluas cakupan layanan pendidikannya tidak hanya untuk bidang pelayanan keagamaan atau pendeta tetapi juga untuk bidang kedokteran dan hukum. Pada abad kesembilan belas, misi pendidikan tinggi di Amerika mulai berubah karena mereka mulai memasukkan mata pelajaran praktis seperti bidang pertanian dan bidang teknik.

Terjadinya Revolusi Amerika tidak banyak memberikan pengaruh terhadap sistem pendidikan tinggi di Amerika, kecuali mengubah beberapa nama. Harvard sedikit berubah pada tahun 1823, ketika George Ticknor, yang saat itu menjabat sebagai kepala lembaga bahasa Modern Smith, menyampaikan pandangannya agar merevisi struktur Harvard seperti apa yang terjadi di beberapa universitas di Jerman. Di antara rekomendasinya adalah bahwa liburan tahunan berlangsung selama musim panas daripada musim dingin. Ketidakpuasan banyak pihak dengan keadaan pendidikan tinggi Amerika menyebabkan 
tuntutan untuk melakukan perubahan kurikulum, tetapi upaya sering ditolak, seperti dalam kasus Yale pada 1828.

\section{Perkembangan Pendidikan Tinggi}

Sampai dengan awal abad ke XIX, perguruan tinggi terus memberikan layanan pendidikan dan program-program baru bagi para pendeta, sehingga banyak perguruan tinggi Katolik serta Protestan yang dibuka pada saat itu (Thattai, 2017). Meskipun fokus utama pendidikan tinggi adalah pelayanan pendeta, pendidikan seni liberal, bahasa Yunani, etika, logika, sejarah, dan matematika juga sudah mulai diberikan/diajarkan kepada mahasiswa. Beberapa universitas mengajarkan materi moralitas sebagai bagian dari pendidikan kader keagamaan. Selain itu, derasnya arus pendatang dari negara-negara Eropa lainnya, seperti Jerman mendorong insitusi pendidikan tinggi menyelenggarakan layanan pendidikan dalam bahasa Jerman, selain dalam bahasa Inggris.

Pada abad ke XX, sistem pendidikan tinggi di Amerika terus berkembang secara pesat. Setiap negara bagian mendirikan perguruan tinggi negeri dan swasta, baik besar maupun yang kecil, yang jumlahnya mencapai tidak kurang dari 3000 perguruan tinggi dan universitas tersebar di seluruh negara bagian Amerika Serikat. Berbagai kebijakan dikeluarkan oleh masing-masing perguruan tinggi dalam mengatur keberlangsungan hidup perguruan tinggi tersebut sehingga mereka mampu manjadi pusat-pusat pengembagan ilmu pengetahuan dan teknologi (Thattai, 2017). Lembaga-lembaga pendidikan tinggi di Amerika saat ini tidak hanya melakukan proses belajar mengajar semata akan tetapi juga mendorong untuk melakukan penelitian dan riset dalam berbagai bidang keilmuan. Jumlah mahasiswa setiap perguruan tinggi bervariasi antara satu kampus dengan kampus lainnya. Sebuah kampus besar bisa memiliki hingga 40.000 orang mahasiswa lebih yang tentunya mampu meningkatkan daya saing dan keberlangsung hidup karena adanya dukungan dana yang besar.

\section{KESIMPULAN}

Puritanisme di Amerika Serikat berintikan nilai-nilai kebebasan individu. Nilainilai itu melahirkan pola-pola kehidupan yang mementingkan kehidupan dari individuindividu dan mementingkan kehidupan bersama yang harmonis. Nilai-nilai kebebasan, demokrasi, dan persamaan yang melahirkan kehidupan bersama tersebut diwujudkan ke dalam ideologi yang merupakan dasar integrasi wilayah-wilayah ke dalam negara Amerika, sebagai langkah Amerika untuk menjadi negara kuat. Secara historis puritanisme berasal dari revolusi Protestan yang berupaya untuk melakukan pemurnian gereja agar kembali pada ajaran kitab Injil. Hal ini timbul karena adanya peranan Gareja Katolik Roma yang menganggap dirinya sebagai satu-satunya institusi yang berwenang mengatur dan mengotrol dunia secara universal. Setiap keinginan individu atau kelompok harus diatur oleh gereja, hanya dengan cara demikian persatuan dapat dipertahankan.

Puritanisme sudah menjadi bagian dari Sejarah Amerika dan membentuk perilaku dasar masyarakatnya. Meskipun pandangan kaum Puritan mengalami pasang surut, namun gagasan-gagasan mereka selalu muncul dalam pidato-pidato pelantikan presiden dari masa kolonial sampai sekarang. Dominasi puritanisme di Amerika memang sudah berlalu, tapi dasar-dasar kehidupan yang mereka letakkan di awal sejarah Amerika telah mengantarkan Amerika menjadi sebuah negara maju dalam segala bidang terutama dalam bidang pendidikan, sehingga dengan majunya pendidikan maka nilai-nilai kehidupan pun menjadi maju, smaka boleh dikatakan bahwa dasar nilai di Amerika adalah inti sari dari ajaran puritanisme, untuk itu bagi bangsa Amerika puritanisme tidak ahanya sekedar 
keyakinan agama semata tapi juga merupakan elemen dasar budaya Amerika dan juga merupakan dasar dari karakter bangsa Amerika.

\section{REFERENSI}

Bercovitch, S. (1998). The Winthrop Variation: A model of American identity. 75-94.

Berghe, M. V. (2018). Is Puritanism still Relevant in Contemporary America? [Ghent University]. $\quad$ https://lib.ugent.be/fulltxt/RUG01/002/478/832/RUG01002478832_2018_0001_AC.pdf

Bolton, R. (1995). The Puritans and Education. Soli Deo Gloria Publications.

Cothran, M., \& Lowe, C. (2011). The classical education of the puritans. Memoria Press.

Craig, C. (2018). Religious Roots for the Puritan Morality Laws [Western Oregon University]. https://digitalcommons.wou.edu/honors_theses/157/

Daniel, B. C. (1990). We shall be as a city upon a hill: John Winthrop's Vision and the Urban History of New England. Trends and Questions in New Historical Accounts of Policing, 19(1). https://doi.org/10.7202/1017588ar

DeMitchell, T. A. (2014). Educating America: The Nineteenth Century Common School Promise in the Twentieth Century.

Gao, J. E. (2014). The Influence of Puritanism on Sin and Punishment in the Scarlet letter. Research on Humanities and Social Science, III (27).

Haris, H. (2010). Metode Penelitian Kualitiatf untuk Ilmu-ilmu sosial. Galia Indonesia.

Hiatt, D. B. (1994). Parent Involvement in American Public School: An Historical Perspective 1642-1994. The School Community Journal, 4(2).

Hiatt-Michael, D. (1994). Parent Involvement in American Public Schools: A Historical Perspective 1642-2000. The School Community Journal, 4(2).

Jernegan, M. W. (1918). Compulsory Education in the American Colonies: I. New England. The School Review, 26(10), 731-749.

Joshua, R. L. (2018). The colonial American economy. https://lib.dr.iastate.edu/ econ_ag_workingpapers/1

Junaidi. (2007). Sejarah perkembangan pemikiran bangsa Amerika. Jurnal Ilmu Budaya, $4(1), 1-65$.

Kang, N. (2009). Puritanism and its Impact upon American Values. Review of European Studies, 1(2). https://doi.org/10.5539/res.v1n2p148

Kenneth, A., \& C. Jr. (2013). Heritage and Hope.

Kim, H. (2019). Salvation by Faith: Faith, Covenant and the Order of Salvation in Thomas Goodwin (1600-1680). Vandenhoeck \& Ruprecht GmbH \& Co. KG, Göttingen.

Kraus, J. W. (1961). The development of a curriculum in the early American Colleges. History of Education Quarterly, 1(2), 64-76. 
Madigan, J. C. (2009). The Education of Girls and Women in the United States: A Historical Perspective. In Advances in Gender and Education (pp. 11-13).

Mahmoud, S. M. (2013). America's Melting Pot or the Salad Bowl: The Stage Immigrant's Dilemma. Journal of Foreign Languages, Culture and Civilization, 1(2). www.aripd.org/jflcc

McGoldrick, J. E. (2010). John Calvin-Erudite educator. Mid-America Journal of Theology, 121-132.

Peterson, R. A. (n.d.). Education in colonial America-The freeman. http://www.thefreemanonline.org/columns/education-in-colonial-america/

Requena, B. G. (2019). Puritan Experience in $17^{\text {th }}$ Century New England: The Witchhunt Episode through the Works of John Winthrop and Cotton Mather. JACLR: Journal of Artistic Creation and Literary Research, 7(1), 56-71.

Saryono. (2010). Metodologi Penelitian Kualitatif dalam Bidang Ilmu Kesehatan. Nugraha Medika.

Setiyadi, B. (2006). Metode Penelitian untuk Pengajaran Bahasa Asing: Pendekatan kuantitatif dan kulaitatif. Graha Ilmu.

Shipton, C. K. (1958). The Puritan Influence in Education. William and Marry Quarterly.

Skeete, G. J. (2010). The Role of Education in New England Puritan Society. Boston Seminar.

Thattai, D. (2017). A History of Public Education in the United States. SRM Institute for Science and Technology. https://www.researchgate.net/publication/321179948

Vinovskis, M. A. (1987). Family and Schooling in Colonial and Nineteenth Century America. Journal of Family History, 12(1-3), 19-37.

Vorster, J. M. (2016). Marriage and Family in View of the Doctrine of the Covenant. HTS Teologiese Studies/Theological Studies.

Yuliati, E. (2015). The Puritan Doctrine and Its Impact to the Society in Nathaniel Hawthorne's novel the scarlet letter [Semarang State University]. https://lib.unnes.ac.id/20797/1/2211411005-S.pdf 